\begin{tabular}{|l|l|}
\hline León Rozitchner: un pensador latinoamericano del presente & Titulo \\
\hline Cabezas, Oscar Ariel - Autor/a; & Autor(es) \\
\hline $\begin{array}{l}\text { De Raíz Diversa. Revista Especializada en Estudios Latinoamericanos (Vol. 2 no. 3 } \\
\text { ene-jun 2015) }\end{array}$ & En: \\
\hline México D.F. & Lugar \\
\hline $\begin{array}{l}\text { Programa de Posgrado en Estudios Latinoamericanos, Universidad Nacional } \\
\text { Autónoma de México }\end{array}$ & Editorial/Editor \\
\hline 2015 & Fecha \\
\hline $\begin{array}{l}\text { Economía; Política; Capitalismo; Cristianismo; Teología política; Teología; Rozitchner, } \\
\text { Leo\&\#769;n; América Latina; }\end{array}$ & Temas \\
\hline Artículo & Tipo de documento \\
\hline $\begin{array}{l}\text { "http://biblioteca.clacso.edu.ar/Mexico/ppel-unam/20160621042206/Cabezas_Oscar_Leon_Rozitchner_un_pensador_latinoamericano_de } \\
\text { I_presente.pdr" }\end{array}$ & URL \\
\hline $\begin{array}{l}\text { Reconocimiento-No Comercial-Sin Derivadas CC BY-NC-ND } \\
\text { http://creativecommons.org/licenses/by-nc-nd/2.0/deed.es }\end{array}$ & Licencia \\
\hline
\end{tabular}

Segui buscando en la Red de Bibliotecas Virtuales de CLACSO http://biblioteca.clacso.edu.ar

Consejo Latinoamericano de Ciencias Sociales (CLACSO)

Conselho Latino-americano de Ciências Sociais (CLACSO)

Latin American Council of Social Sciences (CLACSO)

www.clacso.edu.ar
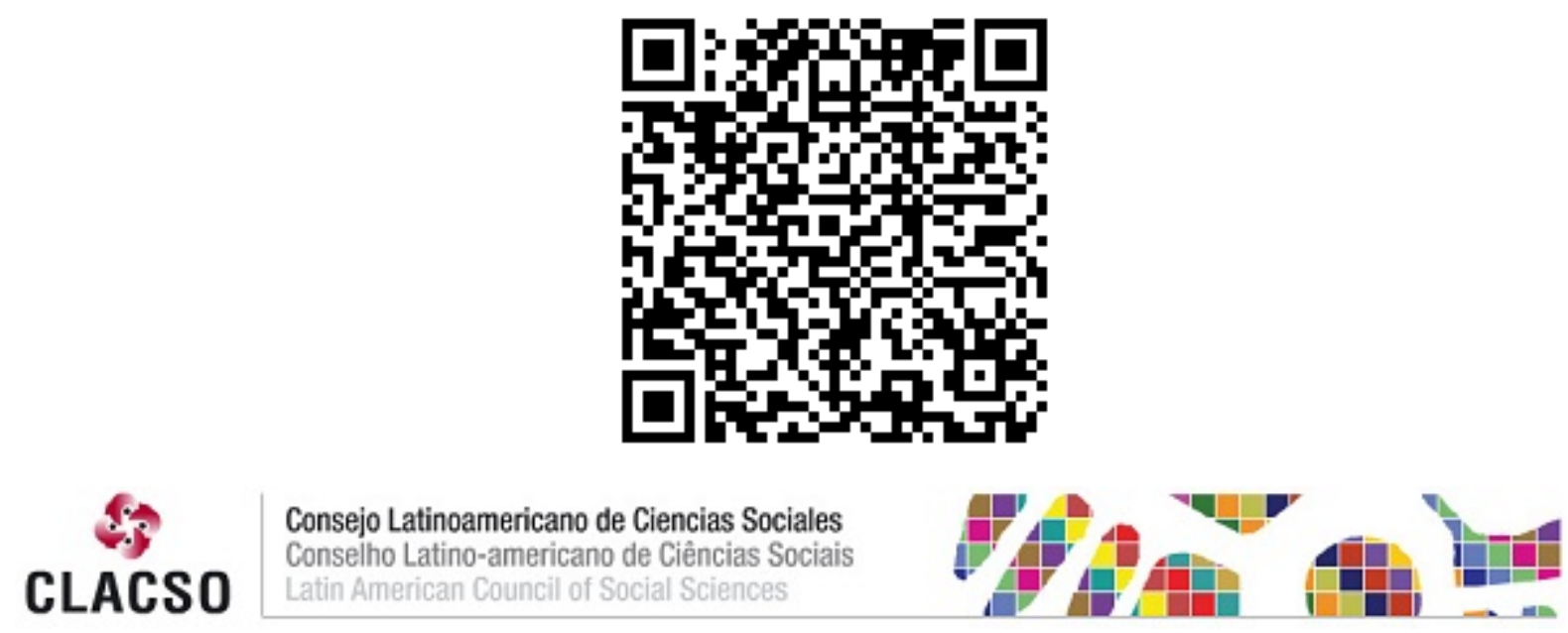


\section{León Rozitchner: un pensador latinoamericano del presente*}

Oscar Ariel Cabezas ${ }^{* *}$

Resumen. Uno de los filósofos de mayor profundidad que han surgido en América Latina es, sin duda León Rozitchner. El reciente interés que ha suscitado su obra se debe a que fue uno de los pioneros en señalar la "cuestión cristiana", como uno de los mayores temas a reflexionar sobre la relación entre política, economía y teología. Este trabajo ofrece una panorámica de la obra de Rozitchner poniendo énfasis en su peculiar manera de abordar el tema de la dominación dentro de un horizonte cristo-capitalista. De igual manera reflexiona sobre el proceso de construcción de una subjetividad servil dentro de los marcos de una teología política en lo que se denomina como una geofilosofía.

Palabras Clave: Geofilosofía, cristo-capitalismo, cristianismo, política.

Abstract One of the deepest philosophers that have emerged in Latin America is undoubtedly Rozitchner León. The recent interest shown in his work because it was one of the pioneers in point it "Christian issue" as one of the major themes to reflect on the relationship between politics, economics and theology. This paper provides an overview of the work of Rozitchner emphasizing its peculiar way of addressing the issue of dominance within a Christ-capitalist horizon. Similarly reflects on the process of building a servile subjectivity within the framework of a political theology in what is termed as a geofilosofía.

KEYWORDS: Geofilosofía, christ-capitalism, Christianity, politics.

Recibido: 11 de noviembre de 2014. ACEPTAdo: 10 de diciembre de 2014 .

\footnotetext{
Algo que conmueve en la escritura de León queda inevitablemente sin respuesta. Algo que no podemos dejar de interrogar en sus escritos, aunque sospechemos que no será en la letra donde descifraremos la respuesta última que buscamos. Algo que nos remite - a través del texto-a una esfera de animación que ya no pertenece a los signos impresos en el papel, sino a otras superficies de inscripción más hondas.
}

Diego Sztulwark (2011)

\footnotetext{
Este artículo no hubiese sido posible sin la generosa invitación que María Pía López me extendiera para participar en las Jornadas León Rozitchner. Contra la servidumbre. El texto que el lector tiene ante sus ojos es una versión ampliada de la ponencia que presenté en dicho evento.

** University of Bristish Columbia <oscar.cabezas@ubc.ca>
} 


\section{$\mathrm{L}$} eón Rozitchner no es sólo un filósofo latinoamericano cuya originalidad pueda ser apropiable por los dominios metropolitanos (o no) de producción de saberes y archivos periféricos, es también uno de los pensadores más importantes del siglo veinte y de comienzos del siglo veintiuno. Su obra se sitúa junto a una variada constelación de filósofos que pensando, desde la singularidad de sus condiciones materiales de existencia, trascendieron sus espacios nacionales y fronteras disciplinares. En efecto, la figura de Rozitchner es tan importante como la de Ludwig Feuerbach, Karl Marx, Baruch Spinoza, Franz Rosenzweig, Gilles Deleuze, Félix Guattari, Bolívar Echeverría, Patricio Marchant, Alain Badiou o Jacques Derrida. La biografía de Rozitchner co-pertenece con la historia de la Argentina - sus tragedias políticas, sus exilios y desventuras emancipadoras - pero la potencia de su pensamiento va más allá de su inscripción regional y nacional; el pensamiento de Rozitchner es universal. En sus libros es reconocible la estela y el brillo de uno de los más avezados espadachines de la crítica teórica, social y política. Lo que Marx llamó el "paso de la crítica de la crítica" constituye el motor de su obra política y teórica. Su filosofía es uno de los intentos más serios y elocuentes de crítica deconstructiva a la diagramación de las formas inconscientes y sensibles de control, producción y administración de los afectos construidos por la dominación teológica. Por eso, se puede entender que su pasión por las fuentes cristianas de la dominación capitalista esté - como diría Walter Benjamin - siempre en el aquí y el ahora de la política. Pensamiento y política son para el filósofo de la mater-materialista, la condición de la "autenticidad" de la crítica que carcome, con la sagacidad de las termitas, un presente aún oprimido por los fantasmas teológicos del universalismo cristiano.

Hay pensamiento crítico en la obra de Rozitchner porque su discurso se sustrae a la condición universitaria de los saberes; sus libros nada le deben a la condición de los conocimientos institucionalizados ni tampoco su filosofía es reconocible en el academicismo especulativo y estético de los discursos universitarios de época. Por el contrario, su pensamiento es una especie de pincel que desempolva las capas de los compuestos invisibles y abstractos que dieron forma histórica a un cristo-capitalismo capaz de metamorfosearse y de producir la barbarie civilizatoria que nos trama como contemporáneos de una falsa universalidad. De acuerdo con Rozitchner, la universalidad del cristianismo seguiría gobernando desde el discurso 
oficial de las instituciones seculares y, sobre todo, desde lo más íntimo e imperceptible de la subjetividad herida y cincelada por la abstracción que olvida la materia sensible. Rozitchner es un pensador de la subjetividad que compone y re-compone teológicamente la fuerza espiritual del capitalismo al mismo tiempo que impulsa procesos de de-subjetivación o procesos de subjetivación capaces de interrumpir la dominación cristiana de los hábitos naturalizados en prácticas sociales y discursivas. Este impulso de escritura política y teórica puede encontrarse en prácticamente toda su obra y fundamentalmente en sus libros La Cosa y la Cruz. Cristianismo y Capitalismo. En torno a las Confesiones de San Agustín (1997) y Cuestiones cristianas (2013). ${ }^{1}$ Desde una analítica freudomarxista - similar, en muchos sentidos, a la que emprendieron Wilhelm Reich o Herbert MarcuseRozitchner deconstruye las fuentes institucionales e imaginarias de lo que vendría a ser el núcleo de la subjetividad dominante. Se trata del núcleo místico-mitológico de la universalidad abstracta alojada en la subjetividad y de la escisión que hiere a la materia desde el correlato cristiano de la formación social de la intimidad.

En uno de sus libros más importantes, Freud y los límites del individualismo burgués (1971), mostrará que la concordancia entre cristianismo y dominación capitalista es la fuente de la formación abstracta de la subjetividad y de las instituciones que la sostienen:

Vemos ya en qué consiste la ilusión en la iglesia: una organización colectiva dónde los individuos no están integrados en una universalidad real, sino en un símbolo de persona invisible - Cristo- que se pretende universal, y hacia el cual todos convergen (447).

Más allá de si era o no un lector de Jacques Derrida, en la reunión del "Todos" con la universalidad abstracta, el trabajo de Rozitchner es deconstructivo en la exacta medida en que desempolva las capas de una espesa forma histórica de la teología y de esta manera, orienta la política de la emancipación hacia la apertura de procesos de des-subjetivación que ocurren individual y colectivamente poniendo en crisis la subjetividad cristo-burguesa y liberal. La "fundación del universal" cristiano, como diría Alain Badiou, sería para Rozitchner la fundación de lo invisible

1 Este texto, recientemente publicado por la colección de la Biblioteca Nacional, es una respuesta a la filosofía de Alain Badiou. El libro puede también ser leído como forma hermenéutica de des-subjetivación de la propia subjetividad de San Pablo y, así, de los hábitos que dan forma a la subjetividad presa por la teología cristiana. 
abstracto que perpetua la servidumbre cristo-capitalista del presente. Todavía hoy, desde sus destellos residuales y secularizados, el cristianismo sería el modelo de articulación del poder que reprime la materia sensible de las relaciones sociales desde los lugares más recónditos de la subjetividad. En otras palabras, los cortes en la conciencia, la domesticación sexual del cuerpo, la disciplina del trabajo, las formas de explotación, la cultura confesional y postconfesional predisponen la organización colectiva e individual de lo social cancelando la actividad sensorial fundada en lo que para Rozitchner constituyen formas originarias de la mater-ia. Así, desde la orillas del Occidente criollo, el filósofo argentino levanta desde lo más profundo de la cultura una filosofía mater-ialista capaz de replegarse deconstructivamente en formas imperceptibles de la ideología y, a su vez, de impulsar la singularidad de las luchas sociales y políticas por la redefinición de lo que Michel Foucault llamó la "ontología del presente".

Por un lado, la obra rozitchneriana mantiene diálogos con lo mejor de la filosofía de Marx, Freud y Clausewitz, y por otro, con Levi-Strauss, Goldman y, especialmente, con quien fuera uno de sus principales maestros, Merleau-Ponty. Además, de lo notorio que es la presencia de Marx y Freud en su obra $-\mathrm{y}$ sin los cuales no puede entenderse en qué sentido su trabajo deconstruye la relación entre cristianismo, subjetividad y capitalismo-la presencia de libros como Humanismo y terror (1947), Fenomenología de la percepción (1945) y Lo visible y lo invisible (1964), entre otros, es indicativa de la enorme influencia que ejercieron en la reflexión de Rozitchner. Por eso, quizá, la militancia y el sentido que esta palabra tiene en la bio-grafía de Rozitchner no puede entenderse al margen de Merleau-Ponty, puesto que en ambos la filosofía constituye la experiencia del pensamiento atada a la militancia política y al trabajo teórico como incisión en las cuestiones de la composición del presente. En esta estela, la filosofía sólo es pensamiento mater-ialista cuando esta va agenciada en la experiencia de la palabra, la cual es para Rozitchner inmanente a la política. Marianela de Sousa Chauí, por ejemplo, dirá que la experiencia del pensar en Merleau-Ponty y, así, la del propio Rozitchner está vinculada al nacimiento de la palabra y a la vida como experiencia político-sensible. De esta manera, lo que acompaña a la filosofía como compromiso militante con la existencia no es la palabra abstracta de la teología o, lo que es más o menos lo mismo, del discurso universitario sino la experiencia sensible de la carne. Tanto en Rozitchner como en Merleau-Ponty, la palabra viva se constituye en el compromiso de la filosofía como inmanencia a la vida 
sensible de los cuerpos y de la política. Por tanto, atado a la vitalidad de los cuerpos, el pensamiento crítico y deconstructivo puede dar forma a la política de las experiencias colectivas en la medida en que la filosofía sólo piensa cuando está agenciada en los movimientos de lucha; sin esta agencia, su labor es un mero ejercicio estético, la consumación de la palabra muerta y, así, la filosofía como parálisis. En el lenguaje de Rozitchner la palabra que emana del centro del orificio de los rostros compone la condición sonora de su potencia en tanto palabra viva movilizada contra el impulso abstracto y especulador de la subjetivad servil. Contra la servidumbre y el poder que silencia y enmudece la materia para enajenarla de las experiencias originarias, la palabra viva despierta a la actividad sensible del mundo y de sus posibilidades o imposibilidades de transformación. La política que habita la memoria arcana de la materia sensible se sustrae de la subjetividad desmaterializada. En tanto servidumbre e inevitablemente subordinada al dominio de lo abstracto, la desmaterialización a la que la vida sensible está expuesta puede golpear, torturar, explotar los cuerpos expropiados por la vida del capital hasta desgarrarlos, hacerlos desaparecer, sangrar y/o evaporarlos en la vampirización a la cual la eco-nomo-teología abstracta del cristo-capitalismo somete los cuerpos. Tendrían así, en la obra de Rozitchner, la expresividad del pensamiento crítico y de la política un carácter inmanente a las experiencias de la carne $y$, por lo mismo, a la expresividad sonora de la palabra viva que se origina individual y colectivamente en las vibraciones del cuerpo. A propósito de Merleau-Ponty, la experiencia de la palabra viva será uno de los temas importantes en Rozitchner. Con la precisión que caracteriza a una de las filósofas más grande de nuestro tiempo, Chauí dedicada a la interpretación de la filosofía de Merleau-Ponty ha enunciado la importancia de la palabra viva de la siguiente manera:

La palabra nace en una doble reflexión: por un lado enlaza los movimientos de la garganta, de la boca, del oído revelando un cuerpo que es sonoro como los cristales y los metales, pero que "oye desde dentro su propia vibración", pues es sonoro para sí. Por otro lado, ese ser sonoro y oyente también es sonoro para otros y oído por otros en la medida que se oye y que los oye, y el lenguaje es el temible poder de crear un locutor que es, simultáneamente, alocutario y delocutario. La experiencia del habla es aterrorizadora porque es la experiencia de un ser que se oye hablando y se duplica porque se dice a sí mismo, que va siendo a medida que se va diciendo, como aquél que, al despertar, dice: "Dormí". (22) 
Sin la expresividad sonora del habla, sin las vibraciones aterrorizadoras de la escritura, las armas del pensamiento desplegado como compromiso militante con la mater-ia no podrían co-existir. En la sonoridad de habla y escritura, la crítica encuentra la hospitalidad de la materia sensible desde la cual Rozitchner entiende el compromiso militante. Este compromiso es lo que podemos definir como la vida sensible de la crítica a la dominación $y$, por lo tanto, a las formas subjetivas que la sostienen desde el espesor ideológico de la actualidad. En la palabra viva, la crítica es así, un modo de habitar el presente y, entonces, de pensar deconstructivamente contra el estado actual de cosas. De manera que pensar, en la filosofía de Rozitchner, es pensar políticamente en la sonoridad de los cuerpos que movilizan la potencia de la vida habitada críticamente por aquello que la acosa y la desmaterializa desde el espesor monstruoso de las entelequias abstractas de dominación cristo-capitalista. ${ }^{2}$

Es la potencia de este pensar lo que le permite a Rozitchner escapar a la mera especulación del filósofo profesional, a la abstracción como técnica de producción conceptual de los estetas académicos, a la generalización vacía de un creacionismo sin creador sensible y, así, sin la actividad sensorial que trama a la mater-ia desde la política como arte de la deconstrucción y de la crítica. En defensa de la experiencia del pensar y de la palabra viva, en el artículo "Justificado para no ir a un congreso de filosofía" dirá - contra la filosofía aristocrática y académica - lo siguiente:

[C] uando el filósofo habla, el "habla habla" con la certidumbre de la teología. [...] Pero para que lo más sensible de nuestra vida pase a la palabra esta necesita siempre de la melodía, la forma primera y arcaica de un cuerpo que se hizo sonido, que organizó el sentido, para que resuene como un eco infinito en los recovecos del cuerpo tensado como las cuerdas de un cuatro. Eso no se inventa. Toda creación es re-creación de algo anterior, un estado de gracia inocente que prolonga ese acontecer originario que abrió el camino para que podamos luego llegar más hondo a la aprehensión del mundo como pensamiento. (2009: 104-6)

En Rozitchner pensamiento y política son el resultado de la condición inmanente a la actividad sensible de una posición ética y no sólo una operación epistemológica del ejercicio del "qué hacer" de la filosofía ni menos

2 El libro de Willy Thayer, uno de los más interesantes sobre el pensamiento de Deleuze y Benjamin, constituye un documento insoslayable para el lector interesado en el tema de la crítica. 
de las filosofías de la vida que funcionan acopladas a los regímenes de producción y control productivo sobre los cuerpos. Sin duda, Rozitchner es uno de los más fieles pensadores de la pasión por la política y su obra es tan significativa como la de cualquier filósofo europeo inscrito en la historia de los destellos de genialidad y gratuidad que sólo puede ofrecer la proximidad con la experiencia del pensar. Sus libros son el testimonio sonoro de la voluntad de pensar y tienen el mismo sonido que aquel que Gramsci, contra las ortodoxias de la teología marxista, denominó "la revolución contra el capital”. Pero Gramsci era un pensador de las condiciones de posibilidad de lo nacional-popular y, en cambio, Rozitchner es pensador de las condiciones de posibilidad o imposibilidad de la deconstrucción de la cuestión cristiana. En otras palabras, su filosofía incomoda a las tendencias nacional-populistas porque deconstruye la teología que funciona como "cemento ideológico" con el cual los Estados nacionales, como entelequias abstractas, se han reunido en el arte de la cohesión seudo-profana o secularizada a medias para asegurar formas de control y dominación del cuerpo social. No entender esto, sería no entender una de sus obras capitales, tal y como lo es Perón: entre la sangre y el tiempo (1998). Libro fundamental para el pensamiento de izquierda argentino, pero también libro universal y latinoamericano para el pensamiento de los desbordes epistémicos y, sobre todo, de la diseminación de la política y del Estado-nación al servicio del arte de la dominación abstracta. Pero Rozitchner no rechaza - como pareciera indicar la moda seudo-anárquica- el Estado-nación sino la condición abstracta de este, es decir, su composición teológico-pastoril. De acuerdo a su filosofía, se puede decir que el porvenir de un pensamiento del Estado y de su permanente acoso y/o toma por parte de los evangelizadores neoliberales y liberales de izquierda sólo puede pasar por asumir la radicalidad de la deconstrucción rozitchneriana de la política como arte del acoplamiento en la vida sin vida del capital y, por lo tanto, en la vida sensible de la materia.

La formación del Estado, en su radiografía más íntima, está compuesta de elementos teológicos, de restos y poderosas ruinas que trabajan en la interioridad de la mimesis con la universalidad vampiril del capital y en los modos de ejercicio de sustracción y abstracción de los cuerpos sensibles de la nación. Por eso, en Cuestiones cristianas (2013) Rozitchner volverá a advertir lo que en sus libros anteriores ya había señalado, esto es, que "el cristianismo niega el fundamento materno-material de la vida 
y expropia las fuerzas colectivas para la acumulación infinita de capital" (12). En esta premisa rozitchneriana podemos afirmar que la intimidad de los Estados-nacionales y lo que, bajo el actual contexto de la dominación planetaria, se ha hecho llamar su condición postnacional está tomada, aunque de manera residual, por las fuentes abstractas del cristianismo. La forma-estado si bien sujeta a la plasticidad con la que esta institución ha variado, su intimidad, la forma cristiana de sus "aparatajes" seudo-seculares dominan hasta nuestros días. ${ }^{3}$ Tomado por la entelequia del falso universalismo cristo-capitalista, el Estado no habría hecho otra cosa que seguir la pulsión tanática de la desmaterialización con la cual el Estado de contabilidad abstracta recrea las formas de organización de lo político. Así, la materia sensible que compone lo nacional, desde la mimesis coactiva y disciplinante de las fuerzas productivas del capital, es abstraída de su pulsión vital. Por lo mismo, si hay parentescos entre la filosofía de Rozitchner y la de Gramsci, estos no residen en el pensamiento hiperbólico del Estado nacional-popular, sino más bien, en el compromiso de una vida militante que siendo fiel a la pulsión de eros de la materia sensible comprehende el mundo que se habita desde configuraciones individuales y colectivas capaces de resistir y diseminar la política de los hábitos eco-nomo-teológicos del capital.

En la maraña profunda de la carne sensible con la que toda nación se compone, Rozitchner establece las premisas con la que se entiende que la relación entre pensamiento y política es indisociable. Esto significa que su filosofía está compuesta de la condición genérica de las experiencias singulares. Sin duda, su obra está inscrita en el pensamiento nacional de la Argentina y de América Latina, habla desde lo singular de la política como acontecimiento local. No obstante, la matriz teórica desde la que articula sus disquisiciones críticas no es la de un pensador de lo nacional-popular, sino más bien, la de un pensador salvaje que afirma la pasión genérica de la política. Pero no porque ésta (la política) pertenezca a los modos abstractos de la universalidad, sino porque está encarnada en la materia sensible de lo social. La actividad sensorial de los cuerpos contra toda tecnología de dominación que niega la vida sensible es el singular-universal del materialismo de Rozitchner. Por eso, quizás Gramsci no constituya

3 Aunque está prácticamente en toda la obra de Rozitchner, este argumento se encuentra desplegado con todo el rigor analítico-deconstructivo en La Cosa y la Cruz. Cristianismo y Capitalismo. En torno a las Confesiones de San Agustín. 
una fuente teórica importante en su obra y sin embargo, su parentela con el filósofo del cuerpo-encerrado y de la hegemonía como lugar del "qué hacer" de la política se encuentra en la paciencia obstinada del trabajo del topo; se encuentra en la intensidad ácida y subterránea del intelectual que no pacta con el orden que domina a través de la administración de lo invisible/abstracto.

Al igual que Gramsci hizo temblar las ortodoxias teleológicas del Marxismo, Rozitchner hace temblar el cemento teológico de los entuertos políticos, de las aglutinaciones sociales, de las identificaciones con lo abstracto, pues lo resquebraja hasta desocultar el Dios invisible de la universalidad del cristianismo. Al mismo tiempo, resquebraja las metamorfosis teológicas devenidas en consignas liberales, tales como la de la célebre mano invisible que regula interiormente los tentáculos del mercado capitalista. La crítica y el desocultamiento de la dialéctica entre lo visible e invisible - posiblemente desde los ecos del habla y la escritura de Merleau-Ponty ${ }^{4}$ - aparecerá como una constante en su obra. En su Perón: entre la sangre y el tiempo, libro en el que se entrelaza su genialidad como filósofo político lector de la ontología del presente y las fuentes teóricas de Marx, Freud y Clausewicz, nos advierte que en el campo de la lucha política, entendida como guerra continuada por medios pacíficos, los hábitos del orden ocultan la violencia anterior a la paz, es decir, anterior a la naturalización del orden mediante técnicas de consenso en las cuales el régimen de invisibilización impone su "fuerza de ley". De acuerdo con Rozitchner la dialéctica entre lo que se ve y lo que no se ve tiene como objeto ocultar la lógica de la guerra (capitalista) sustituyéndola por la ilusión del pacto de la política:

Es porque no estaba incluida la totalidad del ser del hombre dominado en el enfrentamiento de la política durante la paz, y porque la violencia se había hecho invisible como fundamento de la realidad social, y porque ocupábamos el lugar del más débil y nos guiábamos también nosotros por las categorías individualistas del duelo, es por eso que aparecerá la guerra, luego, como puramente militar y no política. Porque la política, que excluía la fuerza, y de la cual se partió en el desencadenamiento de la guerra, se movía en el campo ilusorio de una paz sin violencia, es decir excluida de la guerra. (2012: 149, énfasis mío)

4 Debo está intuición a Karen Benezra, autora de un manuscrito aún inédito en el que se explora de manera crítica la relación entre Rozitchner y Lacan. 
No se trata de una apología de la guerra, sino de su reconocimiento, es decir, de su constatación fáctica como vector ineludible de la composición del orden y sus hábitos teológico-políticos. La "paz" de las sociedades capitalistas invisibiliza la guerra que precede a la consagración del orden. Lo que en las sociedades contemporáneas estaría invisibilizado, hoy más que nunca, son los diferentes estratos de la lucha de clases en tanto guerra social aparentemente pacificada por la cultura hedonista del goce y del consumo. De manera que Rozitchner no sólo habla de lugares donde lo invisible opera ocultando los fundamentos bélicos de la dominación social, sino también de aquellos lugares donde el sujeto - efecto del individualismo burgués y sus límites- vive en la ilusión del éxodo de los antagonismos de clase y bajo la apariencia de que sus padecimientos se superan mediante el duelo por la lucha política y el regocijo en la mercantilización de todas las esferas de la vida sensible.

De acuerdo con este razonamiento, la filosofía de Rozitchner no es sólo la insistencia en la materia arcana del cuerpo que siente, sino también la potencia del pensamiento que se resiste al duelo abstracto promovido por la estructura del intercambio mercantil para sostener la ensoñación del cuerpo sensible que se abre a los mundos negados por la desmaterialización de la vida llevada a cabo por la mercantilización y la elevación fetichista-santoral de los héroes patrios del Estado. De hecho, en uno de sus últimos artículos/conferencias intitulado "Celebrando el segundo Centenario" (2009) nos advierte de la vivencia de la temporalidad y del Estado.

¿[C]ómo temporalizar nuestra propia subjetividad, nuestra propia corporalidad, como para sentirnos más partícipes del tiempo de la historia? Porque las distancias siguen sobreagregándose en las formas que el Estado regula nuestra relación con la historia. La historia de la independencia que uno ha escuchado, leído o aprendido en la escuela, señala más bien la apertura de una distancia incolmable. Frente a los hombres que realizaron la hazaña el ciudadano entra en una relación de reverencia, y por lo tanto de separación humillada. La gloria inmortal de los grandes patriotas convierte en esplendor divino todo lo que toca. (118)

Se trata de un pensamiento de la insistencia y disidencia que no teme interrumpir la topología de las operaciones tramadas por signos, gestos y palabras de una archi-memoria cristiana cuya composición acosa el presente desde el inmanentismo abstracto de las configuraciones del poder. Para producir una práctica filosófica, cuyo impulso es la deconstrucción de las formas abstractas que hemos heredado de la plaga afectiva del cristianismo. Pero la traza de la insistencia y la disidencia que emana de su obra es la 
crítica que da y recibe la forma de un levantamiento, de una insurrección política en el aquí y en el ahora del presente. Lo que hace de Rozitchner un pensador esencial es la pregunta por la cuestión cristiana como pregunta que resuena en el aquí y el ahora de los modos de dominación. En el presente seguirían manifestándose modelos y hábitos políticos de ingeniera social destinados a la producción de lo "des-encarnado". Esto genera la producción estratificada de un cuerpo social dócil y, sobre todo, de un cuerpo social enajenado de la materia sensible. La violencia de la actualidad expresada en el poder del Estado y/o del mercado capitalista, la violencia que se dialectiza en el paradigma de la inclusión y la exclusión serían modos descarnados de violencia contra la vida material de las sociedades. La cuestión cristiana seguiría componiendo los tejidos ideológicos de la afectividad por las vidas abstractas e inmateriales. Los santorales patrios y las divinidades seudo-seculares, las estéticas de la memoria promovidas desde el Estado o desde el mercado, en su intimidad subjetiva, son el falsum, el subjectum de la expresión de una universalidad abstracta que olvida y descarna lo más arcano de la irreductibilidad de la materia. No cabe ninguna duda que en los pliegues del pensamiento de Rozitchner habita el legado y la traza crítica de Marx; pero aquí también co-habita la genealogía de la crítica a lo abstraktum que encontró en La esencia del cristianismo (1841) de Ludwig Feuerbach su punto más temperado contra el universalismo cristiano. En la estela de un pensamiento que busca y se orienta en la deconstrucción de lo abstracto inmaterial como falsa universalidad, la crítica rozitchneriana revela toda su potencia. En su filosofía la crítica y el intelectual crítico todavía son posibles porque el escalpelo de su coraje teórico disecciona las instituciones del poder desde el lugar más íntimo del imaginario que las sostiene. Así, la crítica es el nombre de la deconstrucción del cristianismo y también de la irreductibilidad de la crítica teórica como práctica política agenciada a los movimientos colectivos de lucha por el presente.

A través de las conversaciones con el Colectivo Situaciones la traza de Marx, Merleau-Ponty, Feuerbach, Freud y Étienne de la Boétie, entre otros, será convocada para expresar una idea, una convicción del pensar; esto es, el hecho de que no hay filosofía escindida de la práctica política y de los movimientos sociales. ${ }^{5}$ En otras palabras, la filosofía sólo piensa

5 Agradezco a Diego Sztulwark y Verónica Gago la recomendación de revisar el libro en el que se publicó esta conversación, así como la cariñosa y generosa reunión justo la noche anterior a las Jornadas León Rozitchner, de la cual emanaron varios de los enunciados que componen este artículo. 
plegada internamente en el movimiento. La crítica a los aparatos estatales o supraestatales deconstruye el hábito santoral que modela conductas y domina la materia sensible movilizando la fidelidad del afecto cristiano. En su libro Willing Slaves of Capital. Spinoza and Marx on Desire, Frédéric Lordon muestra de manera rigurosa y conceptualmente creativa que es Étienne de la Boétie el primero en sugerir "la idea de un habitus de la servidumbre" (21). Lo que, no obstante, Lordon no dice es que el hábito está fuertemente vinculado al terror y la gracia como mecanismo que asegura la afectividad de la servidumbre voluntaria mediada por las tecnologías abstractas producidas por la cuestión cristiana. Por eso, a la pregunta por el movimiento del Colectivo Situaciones, Rozitchner responderá con la sonoridad de una voz alegre y sin vacilaciones, vinculando la dimensión afectiva del hábito a la servidumbre: "Si sentís que hasta los afectados por una situación que los destruye no reaccionan y entran en lo que se llamó una 'servidumbre voluntaria', es muy difícil que a uno le pase algo que lo ponga en juego y despierte las ganas de buscar una salida, porque las ganas colectivas estimulan el pensamiento" (2009: 97). El hábito está con-formado por afectos en la medida que la servidumbre voluntaria es un efecto de la cultura cristiana. No es que haya hábitos por un lado y afectos por otro; la afectividad es lo que produce el orden cifrado en sus hábitos y no, necesariamente, una oposición a este. Salir del hábito requiere para Rozitchner un proceso de desidentificación subjetiva con respecto a la cuestión cristiana y, sobre todo, las ganas colectivas (el deseo como impulso vital) del movimiento que interrumpe la normalidad aceptada e internalizada de la dominación.

En la estela de Rozitchner, la filosofía sólo piensa agenciada al afecto de interrupción de los hábitos de reproducción del orden. Por lo tanto, las relaciones entre movimiento y filosofía, entre subjetividad objetivada y alteridad radical son elementos internos a la condición colectiva de una política del pensar que trabaja "desocultando" los lugares donde el hábito del terror y la violencia naturalizada reproducen el patrón del orden cristo-capitalista. En tanto crítica deconstructiva, el pensamiento de Rozitchner es política en acto o, mejor dicho, el acto por el cual pensamiento y política son indistinguibles. Esta indistinción suspende la continuidad de las formas descarnadas de la organización y diagramación social, política, económica e institucional de la pasión (de la izquierda o la derecha) por lo abstracto. Conducida por la crítica rozitchneriana, la suspensión del hábito o, dicho de otra manera, la suspensión de la naturalización de la servi- 
dumbre voluntaria no es ni puede ser pasión y afecto por lo abstracto. ${ }^{6}$ Por el contrario, su filosofía hendida en los surcos de la materia, la escritura y el habla abre la condición afectiva a la posibilidad de un retorno maternal destellante en lo sensible. De manera que la crítica se despliega sobre la anquilosada pasión por la falsa universalidad que, representada en formas y proyectos estatales y/o de mercado, se apodera de lo más íntimo de la subjetividad.

El Estado-mercado de la actualidad, en tanto forma universal de la dominación sobre el socius, encontrará en la potencia enunciativa de la obra rozitchneriana una crítica que escudriña, deconstruye y desoculta aquellas topologías de la enmarañada pasión por el poder de lo abstracto. Este poder, como hemos insistido, reproduce su axioma en la ideología del cristianismo confesional y trinitario de San Agustín y afecta todos lo estratos e instituciones de la vida contemporánea. Por eso, la deconstrucción crítica - atada a la indistinción entre pensamiento y política- cae y se repliega en la interioridad de uno de los principales ideo-teólogos de la retirada de la mater-ia para denunciar la confesión del santo y demoler su ingeniera de dominación abstracta sobre la geo-grafía de los cuerpos. Como movimiento de la crítica genealógica La Cosa y la Cruz cae de la misma manera, es decir deconstructivamente, en la interioridad de los ideologemas de aquellas izquierdas que enajenadas en la compulsión por lo abstracto dejan intactos los modos de articulación santoral de la política y, así, predisponen la máquina estatal a una mera refuncionalización de la relación capital-trabajo. ${ }^{7}$ La izquierda que especula desde el olvido de la materia y desde su imposibilidad de diferir de los pactos con el orden del capital niega la memoria de los afectos primigenios de la mater y abraza la pasión por lo abstracto. En estas operaciones la izquierda se hace parte de la reproducción de los hábitos teológicos con los cuales se obstruye la archi-memoria de lo que nos constituye como sujetos siempre expuestos a la apertura del cuerpo sensible. Esta política de la servidumbre, com-

6 Todas las teorías contemporáneas que hipostasian el lugar de lo inmaterial como política revolucionaria encuentran en las tesis de Rozitchner el clamor de la irreductibilidad de material sensible. Una investigación sobre esta irreductibilidad y los teóricos de la multitud aún está en ciernes.

7 Para un examen más detallado de estas elaboraciones de Rozitchner el lector puede consultar el capítulo tercero del libro Postsoberanía. Literatura, política y trabajo, así como el capítulo quinto del libro Marx and Freud in Latin America. Politics, Psychoanalysis, and Religion in Times of Terror de Bruno Bosteels. 
partida por la izquierda tradicional encontrará su leitmotiv en los modos cristo-romanos de pensamiento político. En este punto - aunque Rozitchner nunca se declaró heideggerino- es inevitable que resuene la famosa frase que Heidegger enuncia en el Parménides: "pensamos la política como romanos" (1992: 43). Esta frase lleva la musicalidad de un Heidegger que busca en el olvido del Ser el sonido griego de la polis, el sonido que habría quedado sepultado por la metafísica y, así, negado al oído de quienes no podemos escuchar ni su eco ni las vibraciones corporales de su emisión. La voz de la política anterior a las abstracciones metafísicas habría quedado escondida en espesas capas de poder civilizatorio mediadas cultural y políticamente por la operación cristo-romana. Así, podemos decir que Rozitchner - aunque no desde figuras ocultas y anteriores al despliegue de la metafísica y tampoco desde el proyecto de destrucción de la metafísica - completa la sospecha de Martin Heidegger advirtiéndonos que no habríamos hecho otra cosa que pensar la política como cristianos. Si bien en Rozitchner no se podría decir que la filosofía de la desprogramación de lo abstracto es heideggeriana, tampoco se puede decir que su pensamiento es anti-heideggeriano y que su filosofía se construye en oposición a las filosofías heideggerianas. La Cosa y la Cruz - libro a la altura de Ser y tiempo (1927) y de cualquier clásico de la historia de la filosofía- condensa la potencia de la deconstrucción hacia la persistente ideología cristo-romana en un claro programa de desprogramación de la cuestión cristiana en tanto artefacto de la reproducción de la servidumbre voluntaria. Esto es lo que hace de Rozitchner un pensador de las urgencias del presente. En su obra la deconstrucción de la ficción cristiana - cuya función es determinar la relación compleja entre materia e ideología para movilizar la violencia y el terror ya no sólo de manera externa sino, obligatoriamente, alojada de manera interna en lo más íntimo de cada persona- abre la política y el pensar al proyecto colectivo de apertura y repliegue en la materialidad de los cuerpos sensibles.

Lo que orienta la relación entre pensamiento y política como responsabilidad por el presente no es la destrucción de la creencia ética en el amor universal, en la pasión de los cuerpos sin diferencia, sino su más acérrima defensa. En efecto, a través de la deconstrucción de los supuestos que organizan la afectividad del orden desde el terror y la gracia, Rozitchner abre la política a sus formas de fidelidad con la carne sensible. Por eso, en la defensa que hace de la homosexualidad y de prácticas sexuales libertarias contra la afectividad de un orden conservador, por ejemplo, Rozitchner 
no vacilará en recordar el ocultamiento de la materia sensible por parte de las incisiones cristianas. Es este intento por dejar escuchar lo que lo une a los intentos de Heidegger por escuchar lo que ha sido cancelado o simplemente proscrito por el poder metafísico de la matriz cristo-romano. En el capítulo "El profeta Ezequiel y los santos varones" de su libro El terror y la gracia (2003) Rozitchner no sólo muestra una enorme sensibilidad hacía la homosexualidad, sino también una de las más significativas e intensas defensas del uso amoroso y libre de los cuerpos. Pero defender la condición material contra las proscripciones del presente le obliga a recordar que el pasado del terror religioso está siempre más próximo de lo que el "presentismo" de la actualidad normalizada está dispuesto a reconocer. Escuchemos lo que dice políticamente y siempre en el devenir de la deconstrucción de las formas abstractas de la ontología del presente:

La Iglesia Católica romana muchas veces prohijó la muerte; instaló el terror moral en el sexo, en lo más elemental y pujante de hombres y mujeres. Esta tradición, por suerte, fue excluida de sus costumbres y sustituida por métodos más persuasivos. Monseñor, en cambio, actualizando esa estela, cita al profeta Ezequiel para traernos de nuevo la imagen de la muerte como castigo merecido para el pecado. No es extraño que acuda a uno de los profetas judíos que esgrime las amenazas más sanguinarias y crueles para marcar con el terror humano la ley divina del cuerpo. (2003: 206-7)

La religión y la condición romana del pensamiento político constituyen la matriz abstracta de formación de la cultura y de sus modos de producción de la servidumbre voluntaria. Esto ocurre en el dominio de la paradojal distancia del "tan lejos tan cerca". Esta paradoja de la historia y de la distancia histórica determina hasta nuestros días modos de hacer y de entender la relación entre subjetividad y política. Por tanto, no es sólo el "mundo cristiano-católico" el que - como el del inquisidor que condena la homosexualidad en el aquí y el ahora de la actualidad- cancela la subjetividad que libera la carne sensible, sino también cierta izquierda a la cual su inconsciente político sigue atado a formas teológicas que, residual o abiertamente, constituyen el nudo de sus prácticas tanáticas. Este nudo tanático se aloja en la misma "plaga de la fantasía" cristo-romana de tendencias progresistas, revolucionarias y/o conservadoras. En el trabajo cristo-romano de la cultura y, por lo tanto, en las formas de dominación abstracta de la materia sensible Rozitchner encontrará las expresiones más reaccionarias de la militancia teológico-política, sean estas de izquierda o de derecha. De manera que su pensamiento no debe ser comprendido 
como la confrontación de una teología-política contra otra. La obra de Rozitchner no es teológica ni menos su pensamiento el lugar de la política teologizada en nombre de la servidumbre voluntaria. Por el contario, su filosofía constituye una de las más intensas prácticas materiales de pensamiento deconstructivo de la teología en cualquiera de sus manifestaciones incluyendo, por cierto, la teología judaica. Rozitchner no es un teólogo del concepto, sino un filósofo político que reacciona contra la traducción de los hábitos seudo-seculares con los cuales las formas burguesas y/o abstractamente populistas de organización del socius articulan el poder de una milenaria teología que persiste desde la interioridad misma de la cultura secular.

En nombre de presupuestos cristianos que dividen el cuerpo del alma, el temblor más íntimo de la subjetividad lleva la marca teológica de una escisión capaz de retirar la materia sensible. La materia dolida, hecha de carne y hueso es atravesada por los fantasmas de la abstracción predisponiendo así, a los sujetos a la servidumbre voluntaria y a la violencia des-carnada. Los predispone o los despliega en la sumisión del habitus y de los afectos de un orden que no se ha emancipado de sus fuentes cristiano-romanas de articulación del poder. Desde el fervor religioso - el cual Durkheim también había entendido muy bien-, metamorfoseado en las estructuras del goce y del pluralismo liberal-protestante de las narrativas culturales del capital, la actualidad del Estado-mercado y sus instituciones regula los cuerpos, los anima a la servidumbre producida por las introyecciones numinosas de un capitalismo cristo-romano que no deja de componer el tejido internalizado y naturalizado de nuestro presente. Estas introyecciones constituyen cortes y escisiones inmanentes a la estructura de la división del trabajo capitalista. Esto explica que la ontología del presente se constituya a partir de una cultura enajenada en la desmaterialización de los cuerpos y, por lo tanto, enajenada de la vida en común.

La filosofía de Rozitchner es materialista en el sentido de aquel marxismo de la crítica de la economía política y del trabajo enajenado como retirada de la materia sensible. Por eso, el pulso de su escritura suspende las concesiones a los fervores abstractos y desoculta sus complicidades con la lógica de un cristianismo internalizado y convertido en habitus. Como premisa de que la historia de la explotación le ocurre a un sujeto o, más bien, a la materia subjetivada en el interior de procesos de producción material de la existencia y conformación de hábitos, no es casual que su 
filosofía siga la estela del Marx de los Manuscritos económico-filosóficos de 1844 y de la Cuestión judía de 1843; pero también hay, sin duda, en su análisis un lazo que lo vincula a Max Weber y la manera como vinculó la ética protestante con las formas de espiritualización o animación del sujeto de explotación y la división del trabajo capitalista.

Desde un marxismo jovial, la filosofía rozitchneriana se orienta en el trabajo con las preguntas originarias concernientes a los hábitos que cancelan, ocultan o reprimen la actividad sensorial de la materia. Este trabajo de la hermenéutica afectiva y del análisis que busca interrumpir en la política la consagración de los hábitos es algo que también lo llevará a situar los procesos de subjetivación de manera material en la condición irreductible de la superficie de la Tierra. En la filosofía de Rozitchner hay una geofilosofía capaz de confrontar la hegemonía del ecologismo abstracto de nuestra época y enajenar en nombre de la naturaleza la materia sensible y sus condiciones materiales de existencia. En su artículo "La negación de la conciencia pura en la filosofía de Marx", publicado en La Habana en 1962, nos dirá:

[L]os verdaderos límites de la universalidad [política], los verdaderos límites materiales de la universalidad sólo se logran abarcar, con el advenimiento del capitalismo, la totalidad de la Tierra. La Tierra es el límite de la extensión máxima del marco de la universalidad de la conciencia, en tanto abarca la totalidad de seres susceptibles de revelar e incidir, desde cada perspectiva personal, en la constitución de nuevas relaciones con el mundo y con los hombres. (44)

En efecto, lo originario no es sólo la madre negada por la filosofía como materia de la cual emana la condición primigenia de todo acto sensible, el cuerpo de la Tierra también se encuentra olvidado en las formas de la acumulación del capital y, sin embargo, es el modo de producción capitalista el que ha hecho posible "nuevas relaciones con el mundo y con los hombres". Aquí Rozitchner aparece no sólo como un filósofo que piensa con los "pies en la Tierra", sino como un geógrafo que expone la relación entre la filosofía y sus relaciones con el hábitat. En la medida que escribe preocupado sobre cuestiones que son elementales para pensar el hecho de que la Tierra es la superficie de inscripción del hombre en tanto ser genérico, su filosofía deviene geofilosofía. Para Rozitchner no es posible imaginar la existencia, la liberación de la materia sensible, contra las formas de servidumbre y explotación sin la consideración del cuerpo 
geológico de la Tierra. La relación con el modo de estar en el mundo y la actividad extendida a los habitantes del Globo Terráqueo como condición de la universalidad concreta hacen de Rozitchner no sólo un pensador del presente, un pensador preocupado por la eco-existencia con los otros, sino y sobre todo un geofilósofo. La geofilosofía de Rozitchner, sin embargo, no estaría relacionada con la metafísica de los orígenes ni con la compulsión melancólica del regreso a una morada auténtica, ni menos aún, como en Heidegger, a la idea de que "sólo un nuevo Dios nos puede salvar" de los males desatados por la tecnificación de la vida. Por el contario, la geofilosofía rozitchneriana es la inscripción de la materia-humana, olvidada o abstraída por la violencia de la división del trabajo y la explotación capitalista en el cuerpo de la propia filosofía. El olvido de la Tierra es la falta de memoria de que la eco-existencia de la materia sensible, de la co-existencia del humano por lo humano, no puede de ninguna manera resolverse en la privatización de la Tierra. Pues ella, en la radicalidad de su condición femenina y materna - marcada, incluso sintácticamente, en lengua castellana por el artículo la- pertenece a la ofrenda que desde su inmanencia absoluta hace posible la co-existencia en común. Lo común sólo puede realizarse en la superficie de este cuerpo lleno y en el hecho no-natural de las relaciones entre el mundo y los hombres, entre los cuerpos y sus significaciones imaginarias.

Las tesis geofilosóficas de Rozitchner se adelantan a las reactualizaciones de las filosofías contemporáneas. El libro titulado La vida sensible del filósofo y discípulo de Giorgio Agamben, Emanuele Coccia, por ejemplo, notoriamente inspirado en las concepciones de la fenomenología de la percepción de Merleau-Ponty nos dice: "Nuestro ser en el mundo no tiene en absoluto el carácter de ser lanzado al mundo ni el de un simple ser ahí. El hombre tiene una relación con el mundo similar a la que todo animal tiene con su propia piel. El mundo no cesa de devenir nuestra segunda piel" (126). Coccia parece evocar aquí la célebre frase de Paul Valery "lo más profundo es la piel”, frase que Rozitchner desplegará como relación entre la materia sensible y la concepción de que los cuerpos están, co-existen y se expresan en la extensión de la Tierra. Aunque Coccia no menciona a Rozitchner su libro sobre La vida sensible se inscribe en el registro de su geofilosofía, pues el parentesco resuena de manera intensa cuando Coccia explicando la expresividad del vestir dice: "Todo vestido tiene algo de uterino. Este es aquello junto a lo que reformamos nuestro estado de huevo" 
(127). En la obra de Rozitchner, no obstante, inquieta la pregunta sobre las condiciones e ideogramas que perpetúan la dominación voluntaria y se hace temblar lo más arcano de nuestras políticas del vestir. Rozitchner, como ya hemos señalado, encuentra en la determinación cultural del cristo-capitalismo las formas de negación de ese algo uterino que advierte Coccia. En La Cosa y la Cruz, libro anterior al Reino y la Gloria de Giorgio Agamben y que Coccia parece desconocer, la deconstrucción crítica del dispositivo cultural del cristianismo muestra como la máquina teológica de este artefacto es capaz de reproducir la vida sensible como acto de sujeción voluntaria negando la cercanía con ese "algo uterino" que el joven filósofo italiano ve en la vestimenta. En Rozitchner, como demostración teórica y de ejercicio de lectura, la explicación de lo que hay de voluntario en la aceptación de la servidumbre está desplegada en su lectura de San Agustín y en su interpretación no parará de advertirnos que la materia sensible está mediada por entelequias sexuadas que hemos internalizado. Estas mediaciones, que componen y producen el deseo, el amor, el afecto, la amistad, la solidaridad, la política han sido metamorfoseadas por las leyes abstractas que pasan a constituir la condición inmaterial, los órganos sin cuerpo, la desafección, la aflicción y el dolor de la materia como drama o melodrama administrado por la dominación del capitalismo cristiano.

De acuerdo con Rozitchner la producción de la subjetividad servil se encuentra articulada por dos tipos de circuncisión religiosas. La primera pertenece a las prácticas rituales y culturales del judaísmo, es externa y configura el ritual judío de la circuncisión del pene. El corte en la carne viva hace posible una política de la identidad comunitaria. Este ritual que regula el cuerpo de la comunidad de creyentes no habría sido suficiente para que el dominio en tanto universalidad abstracta se extendiera sobre los límites de la Tierra. En otras palabras, la geofilosofía de Rozitchner afirmaría que el globo terráqueo como espacio de comunidades compuestas por distintas inscripciones territoriales no podría haberse generalizado sin el corazón circuncidado por el cristianismo. Esto quiere decir que Rozitchner le otorga al cristianismo la producción de una facticidad con el poder simbólico y universal de provocar una incisión, una circuncisión en la subjetividad de los habitantes del "globo". Esta segunda circuncisión operada por las entelequias del cristianismo - en las que no podemos detenernos demasiado- es el modo en que el corte, la incisión en la interioridad del órgano de la materia, el corazón, ocurre como can- 
celación de la carne sensible. Esta tesis de Rozitchner permite sostener que la circuncisión del corazón a partir de la imagen trágica de Cristo y de su novedad es el primer repliegue en la condición aflictiva de una cultura donde el afecto que emana de lo sensible es desplazado, castrado desde la abstracción teológica que en nombre del amor al invisible/abstracto nos predispone al fervor de las guerras genocidas, las masacres, la tortura de la carne originada y originaria por/de la mater. La religión cristiana con sus dispositivos e iconografías celestiales habrían sido movilizadas por la máquina abstracta de producción de poder teológico y de afectos que en el fervor ocultan y/o olvidan la condición sensible de la carne. Así, en Freud $y$ los límites del individualismo burgués aparecerá entrelazada la dialéctica de lo visible/invisible y de lo sensible/racional para corroborar que la vida sensible de la materia padece la premura de algo más complejo que el "algo uterino" de un vestido:

Podemos pasar de lo sensible a la razón si previamente despojamos a la razón del cuerpo que ya no es sólo el de Cristo sino el nuestro. Por eso la idea cuasi-cuerpo, o la cabeza-invisible, cumple su función en la masa artificial: despoja al poder colectivo de su asiento material al disolver las relaciones pensadas separándolas del campo real que las produce, y asienta al cuerpo así separado y negado en la infinitud celeste: en la salvación individual, pero eterna. Astronauta de las ideas, cada uno pierde así su asiento en la tierra -donde el poder aprovecha nuestro poder colectivo. (2013: 471 énfasis mío)

El corazón de Cristo - como topología de cancelación de la vida sensible- queda así cifrado en el lugar biopolítico de producción del rebaño; masa artificial despojada de la Tierra como lugar en común de la co-existencia. Esta operación íntima del poder sobre la vida sensible produce, por decirlo así, la pérdida del suelo terrestre. Jean Luc Nancy repite los argumentos de Rozitchner - aunque sin ninguna mención al filósofo latinoamericano- explicando que el cristianismo ha "desarrollado como ningún otro a la vez una afirmación de potencia, de dominación y de explotación teológico-económica-política" (Nancy, 2006: 65). Según el pensador francés el monoteísmo habría generado - a través del uso simbólico de Roma y de la promesa de lo nuevo- las condiciones de una economía política del poder. En la obra de Rozitchner esta tesis encuentra su mejor actualización porque, precisamente su geofilosofía, va a pensar el entrelazamiento entre la explotación capitalista y las formas teológicas 
de articulación del poder. De acuerdo con el pensamiento de la mater-ia no habría deconstrucción de los presupuestos ideológicos del capitalismo sin la deconstrucción del orden teológico del cristianismo y, al mismo tiempo, no habría continuidad del orden cristiano sin la universalidad abstracta del capitalismo y viceversa. Pero tampoco habría relación de la filosofía de la emancipación y la crítica política sin eso que Daniel Bensaïd llama elogio de la política profana. Pues, si para Bensaïd el presente ha vuelto a caer "en las brumas de lo sagrado y regresa al seno de la teología" (2009: 344) para Rozitchner la incisión del cristianismo habría sido tan intensa que todavía nos encontraríamos afectados por su poder. Por eso, la intensidad de la política profana y la actividad crítico deconstructiva es la condición de posibilidad de que la materia sensible pueda ser desocultada, liberada de la opresión subjetiva que opera en cada uno de los sujetos sensibles. Sin embargo, dicho desocultamiento sólo puede ocurrir a través de acontecimientos que activan la des-narrativización del dispositivo de dominación cristo-romana, es decir, que activan la des-sujetación de la cultura cristo-romana. La entelequia abstracta perdura en el tiempo y en la subjetividad que reproduce la servidumbre voluntaria o, lo que es lo mismo, el habitus de la conciencia cristiano-burguesa, el habitus de la culpa, de la caridad y de la deuda como modos mercantiles de relación con los otros, con el otro. De acuerdo con esta crítica y dentro de una tradición radical de herejes que va de Spinoza a Marx y de Benjamin a Rozitchner, entre otros, lo profano es el nombre de la política y de los procesos de des-identificación como mecanismos subjetivos que hacen corto circuito en el relato que anida, como escalpelo, en los corazones circuncidados por una cultura que privilegia el poder abstracto por sobre la potencia de los cuerpos. Así, la emancipación de la intimidad sería profanación material de la subjetividad cristiana que, residualmente o de manera plena, tiene por efecto la producción de una política del rebaño y de la promesa de que la "Tierra prometida" pertenece a las figuraciones del mundo celeste, pero no a la Tierra en la cual habitamos y co-existimos.

En su libro Ser judío y otros ensayos afines hablará de la nación como el espacio terrenal en común, como existencia con los otros con lo cuales se comparte un mismo suelo de inscripción material. Hablará así del "ámbito geo-gráfico" como definición posible de una identidad des-identificada con los panteones de la patria, es decir, con aquellas figuras sin más cuerpo que la pura imaginería de sus santorales seudo-seculares apropiados 
por la lógica des-carnada del Estado o del mercado. En el juego de las interpelaciones nacionales y de las identidades heridas, el pensamiento de Rozitchner revela su más valiente hendidura en la densidad compleja de los procesos subjetivos que se asientan en las especulaciones del suelo patrio como porción rayada o escrita sobre la Tierra. Lo que hace de Rozitchner un geofilósofo es también su reflexión sobre el pueblo judío. Desde su insoslayable condición de judío y de "orillero" argentino sostiene que el pueblo de Israel habría hecho ingreso a la condición profana, su entrada en la historia en el aprendizaje secular de la "mala" infinitud. El siguiente pasaje tiene la complejidad de pensar la identidad religiosa del judío que hace cortocircuito por lo profano, pero también la complejidad de pensar la incapacidad que hoy tiene un Estado-nación de asumir esta condición. Rozitchner no dejará pasar la intensidad de su crítica hacia los modos de la violencia que el Estado de Israel perpetua con los pueblos árabes y, en particular, contra los palestinos. No obstante, está interesado en el reconocimiento secular de que el pueblo judío tenga un Estado-nación, una nación no-abstracta - realmente secular-, que supone la fidelidad a la posición contra-teológica o, incluso, más radical aún, a-teológica de una geofilosofía que asume radicalmente la condición profana de la Tierra, es decir, de ese pedazo de tierra com-partida que reúne a los pueblos en el nombre de una nación:

Pero el judío aprendió con la historia, por fin, que la "mala" infinitud, la que no se apoya en lo finito y se realiza en él, la infinitud abstracta, no solo es mala para el filósofo que la piensa como un callejón sin salida, como una incoherencia lógica: es mala porque en su mismo planteo mantiene y sostiene la presencia del opresor que impide resolverla. Es mala entonces porque lleva el germen de la negación de la vida aún cuando ayude a mantenerla - quiero decir, porque mantiene la presencia humana de la muerte. Por eso aparece ahora planteada, por fin, en una forma radicalmente distinta: porque los judíos aprendieron el tránsito de la infinitud a la finitud, de lo sagrado a lo profano, de la religión a la historia. De la tierra prometida a la tierra real. (2011: 17)

En oposición a la captura de la subjetividad hecha por la máquina universal del cristianismo, Rozitchner piensa la política profana como una emancipación de todas las formas teológico-políticas que hacen posible la relación entre religión y capital, entre religión y horizonte político-pastoril fundado en la caridad, entre la infinitud de la deuda y la negación de la nación como materia sensible inscrita en la Tierra. Es en la nación como 
materia hecha de carne sensorial donde el oprimido puede encontrar la condición profana de lo que, por ejemplo, el poeta sefardí Edmond Jabès evoca en el verso que dice: "La herida es solidaria con la herida, como la mano con la mano tendida" (2002: 35 ). Se trata de la herida originaria de la mater-ia, pero también de la Tierra rayada, dividida por líneas de exclusión e inclusión según la demasiado frágil condición profana de las modernas soberanías. La proximidad con la herida es solidaridad con la materia desde la condición profana del trabajo político y teórico. El judío que ha sido negado como inhumanidad en lo humano constituye la experiencia de cualquier negación de lo humano por lo humano. Esto hace que la finitud del judío, su casi completo exterminio negado por la humanidad inhumana se extienda a otros oprimidos por el reino abstracto e insensible de la profanación incompleta. En uno de los ensayos del libro Ser judío nos dice:

¿[Q]ué significa ser negado como judío? No digo que esta negación sea igual en el obrero que en el judío; ciertamente más semejante a la del negro que a la del obrero. ¿Por qué? Porque de todas las negaciones humanas, todas las cuales pueden idénticamente ser iguales por sus resultados, llevar igualmente a la persecución y a la muerte, hay una que no tiene nada de común con las otras porque muestra, en quienes la ejercen y la pronuncian, un índice de la irracionalidad del mundo humano más profunda: la negación que se nos infiere no porque poseamos una cualidad determinada, sino la negación que recibimos solamente por el hecho de ser. (23)

La negación por ser, negación a la que llama irracional, abriría a los excluidos, a los negados por ser, al enigma de la existencia como otro, como experiencia de una alteridad, lo cual pone a Rozitchner más del lado de las premisas de Los condenados de la Tierra (1961) de Frantz Fanon que del libro abierto como patria estrellada en el cielo de la poesía del exilio de Jabès. La experiencia límite del judío, del negro y también, en nuestra actualidad la del palestino, conforman el sujeto de la negación como posibilidad real de su finitud. La muerte que en la extensión de la "mala" infinitud condena al existente - a la materia sensible - para asegurar la eternidad en la negación del ser se extiende como necropolítica, como tanatopolítica, desde el momento en que el refugio a la identidad como enigma es también expropiado por la relación entre la cultura de la "mala" infinitud (la eternidad como espectáculo) y el permanente escamoteo de la materia sensible como posibilidad de afirmar la vida más allá de la distinción entre 
finitud y mala infinitud. La política profana debe romper esta dialéctica para afirmar la existencia del ser genérico como premisa no-identitaria de inscripción sobre el cuerpo materno de la Tierra.

La política a-teológica de Rozitchner, sin embargo, no se constituye en la preocupación por el sistema de interpelaciones identitario, sino más bien, en la evocación del ensayo que tempranamente Marx escribe con el título En torno a la crítica de la filosofía del Derecho de Hegel (1844). El sonido de Marx no dejará de resonar en toda la bio-grafía de Rozitchner hasta el punto de que el ejercicio crítico-deconstructivo de su obra tiene como fuente principal la crítica a la religión, es decir, la crítica a las "construcciones imaginarias" producidas por el hombre. Tal como lo piensa Marx "el hombre hace la religión, la religión no hace al hombre. La religión es la queja de la criatura en pena, el sentimiento de un mundo sin corazón y el espíritu de un estado de cosas embrutecido. Es el opio del pueblo" (1974: 67).

En estos enunciados habría que situar la sospecha radical que Rozitchner tiene con respecto a la teología-política $y$, en efecto, a las identidades fundadas desde el trabajo residual de la eternidad teológica sobre la subjetivada, sobre los cuerpos. Pero también a la macabra disección entre la promesa de una tierra prometida y su afirmación de que la Tierra es el cuerpo material de inscripción de la existencia y de la co-existencia con los otros. Su interpretación radical de que el cristianismo es la circuncisión interna del órgano vital de la vida y su confianza en que la política está encarnada en procesos de subjetivación colectivos destinados a des-narrativizar la estructura de la ausencia de mundo, de la ausencia de materia, harían de su geofilosofía la topología teórico-profana de una permanente deconstrucción de los signos y las ilusiones que dominan capitalísticamente la superficie de la Tierra. Se trata de un pensamiento geofilosófico y afectivamente profano porque en su obra, todos los valores religiosos que suplementan la falsa universalidad de capital son retirados desde la crítica al reino y la gloria del opio como fármaco afectivo y de sumisión voluntaria. Se podría decir que la sustancia de este poderoso somnífero será, para Rozitchner, el elemento que se opone a la ensoñación de la mater-materialista. ${ }^{8}$ En efecto, dado que en Marx la metáfora del

8 A propósito del pensamiento y de la relación de este con el ritmo y el poema alojados en el materialismo ensoñado, el trabajo de Diego Sztulwark sobre Meschonnic, Spinoza y Rozitchner es esperado con ansiedad para los lectores de Rozitchner y aquellos que pensamos en la importancia de una desteologización del mundo. 
opio es el punto más temperado del problema religioso y de los afectos mediados y producidos por las intensidades de la dominación íntima de la materia sensible, el opio es el filo que corta la potencia de la subjetividad ensoñada y liberada de su adormecimiento religioso. Así, la condición universal del opio encuentra su eficacia en lo más recóndito del afecto, es decir, en la inducción del somnífero del poder del padre espectral en tanto ley apropiadora que cancela la intimidad. Lo cancelado es la potencia del materialismo ensoñado porque el opio es una forma del olvido en el que lo más arcano de nuestros afectos, de nuestra relación con la materia es removido desde la ilusión abstracta con la que el poder nos afecta. El opio es lo opuesto a la ensoñación, precisamente, por lo que Rozitchner advierte en su libro Materialismo ensoñado (2011):

"El ensueño materno fue suplantado por una pesadilla siniestra, para que siendo grandes seamos como niños de pecho nuevamente. El lugar vaciado de savia materna lo sobrevuela ahora el Padre sin rostro de Hamlet: el resplandor inmisericorde y vengativo del espectro paranoico que acusa a la madre de haberlo traicionado" (25).

El opio en tanto metáfora de la servidumbre es patriarcal y abstracto como la violencia de la ilusión que siempre posterga la mala infinitud de la eternidad.

En el joven Marx esta sustancia que induce a la servidumbre funciona como el fármaco y la farmacia de la subjetividad dominada cristianamente. El opio es lo que adormece, lo que cede al cuerpo sin posibilidad del despertar y, quizá, deberíamos decir con Rozitchner y con cierto Camus y Benjamin, sin ensoñación que recorre, acaricia y anima - desde los pliegues destellantes de la materia - la subjetividad liberada. El opio hace imposible el despertar en/a la materia y, por tanto, es la droga del impasse al materialismo ensoñado y, así, el impasse de una política de la emancipación más allá de la dominación teológico-político-económica de la globalizada evangelización del mercantilismo capitalista. Lo opuesto a la lógica del opio es el ensoñamiento, el despertar a la materia como condición de una política común. Pero este despertar requiere de la crítica como potencia deconstructiva de la matriz que metafísicamente domina y produce el orden diagramado por la cuestión teológica como suplemento privilegiado de los órganos sin cuerpo del capital.

¿Qué es lo abstracto? Lo que no tiene cuerpo, lo que no siente, la mera función de un ordenamiento numérico en las redes productivistas del ca- 
pitalismo. La negación del cuerpo, de la vida sensible es también la negación del orden de lo común negado y suplantado por los espectros patriarcales, invisibles, etéreos y evanescentes del capitalismo actual. La pobre o "nula vida" del afecto no capitalista, no sujeto a las prácticas de la política de la deuda e informado por lo arcano de la materia aún persiste, insiste desde la con-moción, del moverse junto al otro y contra la complicidad que la cuestión cristiana tiene con el gobierno de lo abstracto. El trabajo que des-obra lo abstracto-capitalista sería, en la filosofía de Rozitchner, política y geofilosofía de lo común. Pero la ensoñación como otro modo de ser del afecto no se debe confundir con el comunitarismo identitario, ni con el comunalismo cerrado en sí y para sí de la empresa cooperativa que trabaja sin interrumpir la lógica del capital. La política de lo común no puede ser el cooperativismo del infinito productivo del capital y de sus modos abstractos de acumulación, sino lo enteramente opuesto a las abstracciones del capital como estado de cuentas que retira el cuerpo de la Tierra como atributo de la inscripción de la existencia y co-existencia de lo común, llevada a cabo por la nación abstracta y la evangelización globalizadora de las políticas neoliberales. La política de lo común sólo puede tomar lugar a condición de la deconstrucción de la mitología cristiana que aún, de manera soterrada y residual, sostiene los supuestos ideológicos del orden del capital. Sin el opio que funciona como inmunitas de la política común, la circuncisión del corazón, esto es, la circuncisión del afecto con sus ritmos y velocidades se transforma en el narcótico, el analgésico que en la metáfora marxista del opio, ausculta y anima desde su interior más íntimo las leyes del capital.

En el entrelazamiento con las entelequias teológicas el estado de servidumbre y, al mismo tiempo, el secuestro del despertar en la materia originaria, en la mater, advienen como reino político-teológico. Este permanente advenimiento se asienta en el dominio no secularizado de los Estados y de aquellos que en nombre de una nación abstracta comparten con la ley abstracta del dinero los secretos teológicos del impasse de la política de lo común como deconstrucción de metafísica cristiana. La posición de Rozitchner con respecto a la cuestión del cristianismo es radical hasta el extremo en que en sus postulados no dan cabida a los intentos liberacionistas del social cristianismo. En la filosofía del materialismo ensoñado, los pobres cristianos sujetos a la caridad del estado de cuentas de la "cuestión de la democracia" no constituirían una política de la emancipación porque: 
[c] uando Marx joven dice que el estado tiene "presupuestos cristianos" hay que tenerlo muy presente: la materialidad que se transforma en la producción industrial capitalista, aun "progresista", sigue siendo la materialidad depreciada de la naturaleza, premisa mitológica cristiana, como lo siguen siendo - esto es lo importante- los cuerpos de los trabajadores mismos. Esto implica una racionalidad inmaterial, espiritual, estrictamente cristiana, que con su desprecio domina a la materia para poder construir su riqueza según su teología: la acumulación infinita de todas las cualidades quedan reducidas a la pureza contable cuantitativa. El absoluto infinito que el cristianismo persigue es numerario. Se trata de una materia despojada de todo sentido humano, que es la materialidad que nos ha legado el cristianismo y a la cual nos ha restringido el capitalismo. (104)

En la crítica deconstructiva a la cuestión del cristianismo y, por tanto, al correlato de éste en las democracias del capital también afectan posiciones teóricas importantes como la teología de la liberación y la filosofía misma como culto por lo abstracto. Las filosofías humanistas de la pobreza y aquellas teorías con agencias culturales etnocéntricas resultan ajenas a la radicalidad de una política de la memoria originaria. Lo que Rozitchner llama

[1]a condición primera, que fue vivida como incondicionada por el niño, no puede ser transmutada en un incondicionado filosófico: sería la forma de un pensamiento tan arcaico como el absoluto sentido de la madre ensoñada sobre cuyo vacío la filosofía se piensa con su mitología cristiana" $(2011,46)$

Negada por la filosofía y por la historia misma del capital, aquí la deconstrucción de la mitología moviliza una política de la (re)aparición de la actividad sensorial de la mater y de la mater en tanto superficie de la Tierra. De esta manera la crítica, la polémica ácida y la política constituyen para el pensamiento de Rozitchner la salida del fármaco y, así, la salida de los sistemas inmunológicos de las leyes abstractas con las cuales la teología-política y la economía forman un bloque que sólo puede romperse a condición de procesos de subjetivación profanos. Estos procesos no son otra cosa que la emergencia de lo común como política geofilosófica del hábitat y de la deconstrucción del afecto mediado por la mitología cristiana. Lo que habría de pensamiento radical y transgresivo en la geofilosofía de Rozitchner es una anti-filosofía o una filosofía, si se quiere, que tiene por deseo el intención ensoñado de devolverle a la memoria inmaterial y abstracta su condición material y ensoñada. Es esto lo que 
nos permite pensar que la densidad de un concepto o, mejor dicho, de un anti-concepto como el de la ensoñación hacen de la geofilosofía de Rozitchner un pensador de la política materialista de lo común y, por lo tanto, un pensador contra la biopolítica y los afectos que dominan, desde la condición melodramática del cristianismo, formas actuales de la política y de la teoría con las que se suele pensar la relación entre lo común y la emancipación. En oposición a estas formas y sin ningún romanticismo político habría que decir que Rozitchner es un pensador de la ontología del presente porque en su materialismo ensoñado la política de lo común o de la actualidad del comunismo, la profanación radical es el nombre mismo de la política de lo común. En otras palabras, es el nombre de los comunes que luchan y recrean retirando la miseria que hay en la lógica abstracta e inmaterial del dominio de lo humano por lo humano. En Rozitchner hay un temprano comunismo geofilosófico, un eco-comunismo desde el cual se puede actualizar y re-poner la soberanía de lo común, precisamente en la forma en que lo define en conversación con el Colectivo Situaciones: "La categoría teórica de lo 'general' en Marx, como algo que es común a todos, es pensable porque previamente los hombres han creado la 'propiedad comunal de la Tierra' como una relación social compartida” (2009: 97). Sin embargo, una soberanía de lo común requiere como condición de posibilidad o de imposibilidad no sólo la retirada de los retornos melancólicos al comunalismo de la tierra, sino también del elogio radical de lo profano, como potencia de una geofilosofía materialista y ensoñada que reclama en el aquí y el ahora el porvenir de lo común.

\section{BIBLIOGRAFÍA}

BADIOU, A. (1999); San Pablo: la fundación del universalismo. Trad. Danielle Reggiori. Barcelona: Anthropos.

BENSAÏD, D. (2009); Elogio de la política profana. Trad. Susana Rodríguez Vida. Barcelona: Península.

BENEZRA, K. "Symptoms of the Inorganic: León Rozitchner on Mass Psychology." (Manuscrito)

BOÉTIE, É. (2008); Discurso sobre la servidumbre voluntaria. Trad. Pedro Lomba. Madrid: Trotta.

BOSTEELS, B. (2012); Marx and Freud in Latin America: Politics, Psychoanalysis, and Religion in Times of Terror. New York: Verso. 
CABEZAS, O. A. (2013); Postsoberanía. Literatura, política y trabajo. Buenos Aires: La Cebra.

CHAUÍ, M. de S. (2000); Merleau-Ponty: la experiencia del pensamiento. Trad. Eduardo Rinesi. Buenos Aires: Colihue.

COCCIA, E. (2011); La vida sensible. Buenos Aires: Marea.

FANON, F. (1963); Los condenados de la tierra. Trad. Julieta Campos. México: Fondo de Cultura Económica.

FEUERBACH, L. (1995); La esencia del cristianismo. Trad. José L. Iglesias. Madrid: Trotta.

GRAMSCI, A. (1917); “La revolución contra el capital.” en Avanti.

HEIDEGGER, M. (1951); Ser y tiempo. Trad. José Gaos. México: Fondo de Cultura Económica.

, (1992); Parmenides. Trad. André Schuwer y Richard Rojcewicz. Bloomington: Indiana University Press.

JABÈS, E. (2002); Un extranjero con, / bajo el brazo, / un libro de pequeño formato. Trad. Cristina González de Uriarte y Maryse Privat. Barcelona: Galaxia Gutenberg.

LORDON, F. (2014); Willing Slaves of Capital: Spinoza and Marx on Desire. Trad. Gabriel Ash. New York: Verso.

MARX, K. (1974); Early Writings. Londres: Penguin Books.

NANCY, J. (2006); La deconstrucción del cristianismo. Trad. Alejandro Madrid Zan. Buenos Aires: La Cebra.

ROZITCHNER, L. (1962); “La negación de la conciencia pura en la filosofía de Marx.” Universidad de La Habana 157. pp. 5-41.

(1997); La Cosa y la Cruz. Cristianismo y Capitalismo. En torno a las Confesiones de San Agustín. Buenos Aires: Losada.

, (2003); El terror y la gracia. Buenos Aires: Grupo Editorial Norma.

(2009); "Justificado para no ir a un congreso de filosofía." Lenguas

vivas. Buenos Aires: Biblioteca Nacional. pp. 101-116.

(2009); "Cuando el pueblo no se mueve, la filosofía no piensa."

Conversaciones en el impasse. Dilemas políticos del presente. Ed. Colectivo Situaciones. Buenos Aires: Tinta Limón, pp. 95-134.

131.

(2010); “Celebrar el segundo Centenario” La Biblioteca 9-10 pp. 112-

(2011); Materialismo ensoñado. Buenos Aires: Tinta Limón.

(2011); Ser judío y otros ensayos a fines. Buenos Aires: Losada.

(2012); Perón: entre la sangre y el tiempo. Buenos Aires: Biblioteca Nacional. 
ROZITCHNER, L. (2013); Freud y los límites del individualismo burgués. Buenos Aires: Biblioteca Nacional.

(2013); Cuestiones cristianas. Buenos Aires: Biblioteca Nacional.

SZTULWARK, D. (2011); “Signos corpóreos.” en Página 12.

El ritmo del pensamiento: una lectura de Henri Meschonni. (Manuscrito)

THAYER, W. (2010); Tecnologías de la critica: entre Walter Benjamin y Gilles Deleuze. Santiago de Chile: Metales Pesados. 